\title{
Comparison of Blood Pressure and Pulse Measurements to Tai Chi Exercise in Hypertensive Patients in East Jakarta
}

\author{
$1^{\text {st }}$ Dheni Koerniawan Nursing Science \\ Program, Health Science Faculty \\ University of Catholic Musi Charitas \\ Palembang, Indonesia \\ koerniawan314@gmail.com
}

\author{
$2^{\text {nd }}$ Maria Lousiana Suwarno \\ School Nursing Master Program \\ Sint Carolus School of Health Science \\ Jakarta, Indonesia \\ lousianasuwarno@gmail.com
}

\author{
$3^{\text {rd }}$ Irene Adyatmaka \\ School Nursing Master Program Sint \\ Carolus School of Health Science \\ Jakarta, Indonesia \\ irene_al200@gmail.com
}

Corresponding author: koerniawan314@gmail.com

\begin{abstract}
Increasing prevalence of hypertension (HT) risk factors and number of uncontrolled blood pressure in hypertensive patient still being the focus in health care, especially in nursing promotive-preventive and rehabilitative care. Complementary and alternative nursing care aims to enhance patient awareness and empowerment in unique ways, for instance Tai Chi as mind-body exercise. This study aimed to compare blood pressure and pulse responses of hypertensive individuals to 60 minutes and 30 minutes Yang style Tai Chi exercise with control group. Fifty-seven participants in the study divided to three groups (60 minutes Tai Chi, 30 minutes Tai Chi, and control group) and included by purposive sampling for eighth weeks with once a week session. Blood pressure and pulse were measured in baseline and the eighth week, then analyzed with one-way ANOVA to compare three groups at baseline and eighth week measurements. The result show that there was no significant differences at baseline for all groups (SBP: $p=$ 0.344; DBP: $p=0.118$; Pulse: $p=0.506$ ). However, there was a significant difference at eighth-week measurement for all variables (SBP: $p=0.025$; DBP: $p=0.017$; Pulse: $p=$ 0.016). The study results suggest that Tai Chi is an effective exercise to lower and maintain blood pressure and pulse levels among hypertensive patient, and thus may be potential intervention to control hypertension.
\end{abstract}

Keywords: blood pressure, complementary and alternative care, hypertension, pulse, Tai Chi.

\section{INTRODUCTION}

Hypertension is a noncommunicable disease (NCD) that remain a concern in nursing care management because of its long-term care in nature. One of the significant problems in hypertension management is uncontrolled blood pressure that may be contributed by inadequate preventive and rehabilitative care. Nowadays, nursing care has shifted its focus in promote- preventive and rehabilitative areas. Globally, hypertension prevalence increased from 600 million in 1998 to one billion in 2008 [1], then continue to rise and reached 1.13 billion in 2013 [2]. According to WHO, 1 in 4 men and 1 in 5 women had hypertension in 2015 [2]. American Heart Association (AHA) reported that there were 76.4 million hypertensive patients in 2008 and 77.9 million in 2010, and they estimated that this number would increase by 27 million in $2030[3,4]$. In South East Asia context, $25 \%$ of the population had hypertension [5]. The rising number of hypertensive patient, has increased the burden on the healthcare system associated with hypertension-related complication condition such as heart attack, heart failure, and stroke [4].ICardiovascular disease (CVD) is one of the four main NCD besides cancer (27\%), respiratory disease $(8 \%)$, and diabetes $(4 \%)[6]$. This condition may lead to mortality, which 7.5 million deaths because of hypertension was identified in 2008 globally [3]. CVD has probability of deaths around 17.5 million worldwide and $37 \%$ at age under 70 of age, caused by coronary heart disease (CHD) as 7,4 million deaths, 6.7 million deaths by stroke, and 1.5 million deaths by diabetes [5]. Also, in United States has 20,2\% increasing from 2003 until 2008 with mortality rate 18.3 per 100,000 people and increased to 18,8 per 100,000 in 2009 [3]. Indonesia had $31.7 \%$ hypertensive patients in 2007, and decreased to $25.8 \%$ in 2013 , then increased to $34.1 \%$ in 2018 [7-9]. This condition will continue arise by the increasing risk factors of hypertension in Indonesia, such as high blood glucose, 
obesity, and tobacco smoking uses [5,10,11]. So, this occurred because the under control of risk factors and blood pressure, same as in $47.5 \%$ in United States [4] me important key in the management of hypertension, especially in the area of promote-prevention and rehabilitative such as complementary and alternative care (CAC). Complementary care aims to increase awareness and empowerment patients by utilizing positive aspects and abilities of patients [13]. Warren et al. divides complementary care into three forms, namely products (such as supplements and phytopharmacy), practices (such as acupuncture and massage), and exercise (such as Tai Chi and yoga) [13]. Tai Chi also called mind-body exercise because it is a series of body movements that flows continuously and requires integration of mind concentration, balanced body load changes, muscle relaxation, and breathing control [14]. A study of 39 respondents who did Tai Chi for 12 weeks showed that in the first 6 weeks there was a decrease in systolic blood pressure of $15.4 \mathrm{mmHg}(\mathrm{p}=0.001)$, diastolic blood pressure of $8.2 \mathrm{mmHg}(\mathrm{p}=0.001)$, and pulse rate 1.4 bit per minute (bpm) [15]. The decrease in blood pressure that occurs after Tai Chi training is caused by an increase in baroreflex sensitivity [16], increased parasympathetic nerve activation and decreased sympathetic [17], as well as an increase in arterial compliance and decreased peripheral vascular resistance [18]. In addition, Tai Chi which is low impact because it has a metabolic equivalent value of 1.5-4 METs [19], shows that Tai Chi is safe to do and can be paired with physical exercise interventions that already exist in the heart rehabilitation program (grade B level II) [20]. There were many studies of Tai Chi as therapy for hypertension, but still lack of study how intensity of Tai Chi can affect the blood improvement choices of exercise that can be used as CAM in hypertension management, at the context of intensity of Tai Chi. The Tai Chi program can be make step-by-step session to induced adaptation of cardiovascular regulation to maintain blood pressure and pulse being controlled.

\section{METHOD}

This study used quasi-experimental design to fiftyseven participants as Hsieh formula [21], which divided to three groups: sixty minutes Tai Chi, thirty minutes Tai Chi, and control group. Samples were taken with criterial: age 20-80 years old, diagnosed as pre-hypertension to stage II hypertension [22], not has severe cardiovascular problems such as shortness of breath and chest pain when doing daily activities, not have mobilization and joint impairment, and never done Tai Chi. The intervention will be stopped when participants experiencing shortness of breath, chest pain, and joint pain then excluded from samples. and $68 \%$ in Australia [12].

It shows that the very need of blood pressure monitoring and maintain in stable beco

Yang style Tai Chi exercised for eight weeks with once a week session. Five moves used in this study conducted as main moves from 24-form Yang style Tai Chi which have been used by Yeh to heart failure and chronic obstructive pulmonary disease patients [23,24]. Every session has different duration of main moves to accommodate physiology adaptation to Tai Chi exercise [25]. Blood pressure and pulse measured after 5 minutes from activity and after exercise [26]. Baseline measurement taken from before first session and after last session as eighth week measurement. Descriptive analysis showed in mean and standard deviation (for numerical data), and frequency and percentage (for categorical data). The differences between three groups analyzed by one-way ANOVA.

\section{RESULTS}

Table 1 Distribution of participant's characteristic and baseline measurements

\begin{tabular}{lc}
\hline Variables & Baseline \\
\hline Age & $61.44 \pm$ \\
& 6.62 \\
Gender & \\
Men & 13 \\
& $(22.88 \%)$ \\
Women & 44 \\
& $(77.2 \%)$ \\
Blood Pressure & \\
Systolic Blood Pressure (SBP) & $149.23 \pm$ \\
& 13.688 \\
Diastolic Blood Pressure (DBP) & $87.07 \pm$ \\
& 8.398 \\
Pulse & $83.35 \pm$ \\
\end{tabular}

Distribution of participants' characteristics (Table 1) showed that averaged in old adult $(61.44 \pm 6.62$ years old) and majority are women (77.2\%). Participants has stage two hypertension $(149.23 \pm 13.688 \mathrm{mmHg})$ with normal range pulse $(83.35 \pm 7.173 \mathrm{bpm})$ in average.

Table 2. comparison analysis between all groups at baseline and eighth week

\begin{tabular}{|c|c|c|c|c|c|c|}
\hline \multirow{2}{*}{ Variables } & \multicolumn{3}{|c|}{ Baseline } & \multicolumn{3}{|c|}{ Eighth week } \\
\hline & Mean & $F$ & value & Mean & $F$ & value \\
\hline \multicolumn{7}{|c|}{ Systolic Blood Pressure (SBP) } \\
\hline \multirow{3}{*}{$\begin{array}{l}\text { Su minutes } \\
\text { Tai Chi } \\
60 \text { minutes } \\
\text { Tai Chi } \\
\text { control } \\
\text { group }\end{array}$} & 150.69 & & & 143.19 & & \\
\hline & 152.18 & 1089 & 0.344 & 137.59 & 3.966 & 0.025 \\
\hline & 146.17 & & & 148.92 & & \\
\hline \multirow{4}{*}{$\begin{array}{l}\text { Mrastome sio } \\
\text { 30 mimutes } \\
\text { Tai Chi } \\
60 \text { mimutes } \\
\text { Tai Chi } \\
\text { control }\end{array}$} & arressur & (WEN) & & & & \\
\hline & 86.50 & & & 82.06 & & \\
\hline & 90.47 & 2.224 & 0.118 & 81.59 & 4.420 & 0.017 \\
\hline & 83.04 & & & 85.15 & & \\
\hline \multirow{3}{*}{$\begin{array}{l}\text { Pulse } \\
30 \text { minutes } \\
\text { Tai Chi } \\
60 \text { minutes } \\
\text { tan thi } \\
\text { control } \\
\text { group }\end{array}$} & 84.88 & & & 80.81 & & \\
\hline & 8359 & 0.690 & 0.506 & 77.29 & 4.495 & 0.016 \\
\hline & 82.17 & & & 82.25 & & \\
\hline
\end{tabular}


majority are women (77.2\%). Participants has stage two hypertension $(149.23 \pm 13.688 \mathrm{mmHg})$ with normal range pulse $(83.35 \pm 7.173 \mathrm{bpm})$ in average.

Table 2 showed that almost all groups has decrease measurements in every variable. Moreover, there were not different significantly at baseline measurements in all groups at all variables comparison analysis. It has showed that there were good homogeneity at baseline measurements. Meanwhile, there are significantly differences between all groups at eighth week in SBP $(p=0.025)$, DBP $(p=0.017)$, and pulse $(p=0.016)$.

\section{DISCUSSION}

The central nervous system coordinates the reflex control of blood pressure with the medulla oblongata as the main integration center, then the autonomic nerve will affect blood pressure regulating effectors such as the SA node (pulse regulation), ventricular myocardial, and smooth muscle in the arteries and veins. This function can be modulated by input afferent reflex receptors and stimulation from other central nervous system areas such as the respiratory center, hypothalamus, limbic system, and cerebral cortex.

The increase in blood pressure that occurs in the early weeks of the study shows the physiological adaptation of the body to dynamic aerobic exercise types to increase oxygenation and cardiac output due to increased metabolic requirements. After the body is able to adapt, there will be a post-adaptation condition so that a decrease in blood pressure can be seen. This condition is seen in blood pressure from the fourth to the eighth week.

Blood pressure in the eighth week decreased significantly both in systolic and diastolic blood pressure in the Tai Chi group 60 minutes and 30 minutes (systolic Tai Chi 30 minutes: $X=143.19$; diastolic Tai Chi 60 minutes: $X=81.59$; diastolic Tai Chi 30 minutes: $X=82.06$ ), while a significant increase in systolic blood pressure occurred in the control group ( $\mathrm{X}=148.92)$.

This is supported by Taylor-Piliae, Haskell, \& Froelicher study on 38 respondents who were given Tai Chi intervention for 60 minutes in 12 weeks with 3 meetings each week, showing a greater decrease than baseline size at week six (16 $\mathrm{mmHg})$ compared to the 12th week $(2 \mathrm{mmHg})$. The results showed that at the 12 th week the decrease in blood pressure was more stable (steady / smooth) than the sixth week [15].

The results of $\mathrm{Lu} \&$ Kuo's study comparing 20 respondents of Tai Chi practitioners with more than two years' experience with 20 respondents in the control group, explain how the mechanism of reducing blood pressure in Tai Chi is caused by changes in sympathetic nerve activity and vagal analysis of Heart Rate Variability (HRV). The intervention was given for one hour with a frequency of three times a week. The results show a gradual decrease in systolic and diastolic blood pressure, pulse, mean arterial blood pressure, and pulse pressure. HRV analysis shows an increase in vagal frequency and decreased sympathetic [17]. Therefore, the results of hemodynamic and HRV indicate that a decrease in blood pressure and pulse is caused by an increase in vagal activity and a decrease in sympathetic activity.

The decrease in baroreflex sensitivity (BRS) that occurs in patients with old hypertension causes a decrease in the nervous system response to changes in blood pressure so that the physiological mechanism fails to adapt as indicated by the continued high blood pressure in patients with old hypertension. Therefore, the increase in BRS that was raised by Tai Chi showed an effective effect in lowering blood pressure, as evidenced by the Sato et al. study in 20 coronary heart disease patients with 10 respondents in the intervention group who already had 1 year of experience doing Tai Chi and 10 respondents in the control group. The intervention group was given the Tai Chi Yang style exercise with 8 postures for 60 minutes while the control group with the condition received pharmacological therapy, diit guidance, and physical activity counselling. The study results show that the intervention group experienced a significant increase in BRS ( $\mathrm{p}=0.036)$ with a significant difference in BRS $(\mathrm{p}=0.04)$ to the control group [16].

Muscle metabolism and movement of muscles and joints during exercise have a contribution to the input received by the cardiovascular center through proprioceptors and chemoreceptors. Proprioceptor monitors joint and muscle movements in their contribution as stimulus input to the cardiovascular center during exercise [27]. Low oxygen levels and high levels of carbon dioxide, which triggers an increase in $\mathrm{CO}$ and then increases blood pressure, activate chemoreceptors. The rhythmic, gentle, and slow movement during Tai Chi causes a slow muscular pumping effect on the veins and peripheral arteries to stimulate and train the vascular elasticity. Thus, it can improve arterial compliance and reduce peripheral resistance as evidenced in the Lu et al. study in 65 elderly respondents who suffer from hypertension. The results showed a clear relationship between decreased systolic blood pressure $(p=0.004)$, diastolic $(p=0.019)$, pulse pressure $(p=0.028)$ with increased elasticity of large arteries $(\mathrm{p}<0.001)$ and small arteries $(\mathrm{p}=0.002)$ and 
decreased systemic resistance $(p=0.006)$ [18].

Other effects arising from dynamic foot exercises that are constantly (intense) at moderate levels such as Tai Chi (4 METs) [19] will provide adequate stimulus to reduce sympathetic activation caused by metabolism slow peripheral (metaborelfex- induced sympathetic activation) [16] so that the chemoreceptor response to changes in oxygen and carbon dioxide levels can adapt. Slow and deep breathing that occurs during Tai Chi also has several effects such as respiration pumps (have the same mechanism as muscle pumps), adaptation of chemoreceptors due to an increase in oxygen intake and carbon dioxide release (longer duration during inspiration and expiration), and adaptive systems cardiovascular-respiratory center [28]. The hypothalamus, limbic system, and cerebral cortex contribute to the flight or fight response, emotional, and learning participate in providing input to the cardiovascular center. Therefore, the effect of Tai Chi meditations that provide a sense of calm, comfort, peace, and relaxation become a stimulus in lowering blood pressure, as shown in the results of the metaanalysis of Wang et.at. 23 of 33 RCT studies show that doing Tai Chi for one hour regularly can reduce stress, anxiety and depression and significantly improve mood in healthy adults and in patients with chronic conditions [29].

The differences mean in results show that the intensity of 60 minutes is more effective than the intensity of 30 minutes in reducing systolic blood pressure but is slightly more effective in reducing diastolic blood pressure. This happens because the linearity relationship between hemodynamic changes during exercise and exercise intensity is mediated by afferent modulation (BRS) and effector (vagal nerve) arising from the Tai Chi effect. The longer the intensity of Tai Chi, the modulation takes place more optimally because exposure to afferent and efferent occurs longer so that the process of regulatory adaptation becomes better which is manifested by a decrease in blood pressure.

Cardiac output, pulse rate, oxygen consumption, and systolic blood pressure have a linear relationship with exercise intensity. Adjustment during exercise is the responsibility of the reflexes that cur at receptors and efferent in the mechanism of regulation at the cardiovascular center. At low to moderate training load, the pulse is mediated through vagal rhythm activity [30]. Therefore, the modulation of the autonomic nerve frequency that causes a significant increase in vagal activity will reduce the stimulation of the SA node due to decreased neurohormonal release such as catecholamine resulting in a decrease in pulse rate. This explains the results of this study which showed a significant decrease in pulse in the pulse group in Tai Chi 60 minutes and Tai Chi 30 minutes, while the control group experienced a significant increase. The decrease in pulse rate was also found in the Lu \& Kuo study of 20 respondents who had been Tai Chi practitioners for $1.9 \pm 1$ years. The study results show that the decrease in pulse rate is accompanied by an increase in the frequency of vagal activity and a decrease in the frequency of sympathetic activity [17]. Decreased pulse rate and arterial compliance will result in decreased blood pressure. The Tai Chi effect that increases baroreflex sensitivity will make the body respond to the drop in blood pressure and cause nervous system feedback to decrease the pulse. The process shows that Tai Chi in the end will result in a decrease in blood pressure, which has subtle fluctuations and maintains a stable blood pressure. Therefore, it can be concluded that the short-term effect (short-term) of Tai Chi has been able to reduce blood pressure and the long-term effect (long-term) is to maintain and stabilize blood pressure. Therefore, the more routine Tai Chi exercise is, then the modulation of the autonomic nerve balance between vagal and sympathetic activity can more reduce blood pressure and maintain a stable blood pressure condition [23] as it found at Yeh et al. study. A similar mechanism that occurs with a decrease in blood pressure due to Tai Chi also occurs in the pulse, because an increase in BRS and autonomic nerve modulation will affect stimulation of the SA node so that the pulse rate will decrease.

\section{CONCLUSION}

Tai Chi can be done without the need for special equipment, not limited to age, sex, nutritional status, blood sugar levels, and smoking history. The Tai Chi effect will comprehensively be experienced if the practitioner also lives and practices the philosophical principles of Tai Chi. Therefore, Tai Chi can be one of the appropriate nursing intervention options in reducing blood pressure and pulse as well as increasing power and quality of life whether it can be controlled or monitored independently in the context of institutional clinical practice (hospital) or community, both in promotive and preventive context but also curative and rehabilitative, as well as in physiological, psychological, and spiritual approaches.

\section{ACKNOWLEDGMENT}

This acknowledgment is given to M.L.S and I.A as collaborators of this study. In addition, University of Catholic Musi Charitas especially Faculty of Health Science for funding the publication as proceeding article of oral presentation. 


\section{REFERENCES}

[1] Hypertension Fact Sheet [Internet]. WHO2013;Available from: www.who.int

[2] WHO. Hypertension Fact Sheet [Internet]. WHO2019 [cited 2020 Mar 4];1. Available from: www.who.int/healthtopics/hypertension

[3] Roger VL, Go AS, Lloyd-Jones DM, Benjamin EJ, Berry JD, Borden WB, et al. Heart disease and stroke statistics-2012 update: A report from the American heart association. Circulation 2012;125(1):2-220.

[4] Go AS, Mozaffarian D, Roger VL, Benjamin EJ, Berry JD, Borden WB, et al. Heart disease and stroke statistics-2013 update: A Report from the American Heart Association. Circulation 2014;127(1).

[5] WHO. World Health Statistics 2016: Monitoring Health for The SDGs, Sustainable Development Goals. Geneva: 2016.

[6] World Health Organization. Global Status Report On Noncommunicable Diseases 2014. Geneva: 2014.

[7] Depkes RI. Riset Kesehatan Dasar (Riskesdas) 2007.Jakarta: 2008.

[8] Depkes RI. Riset Kesehatan Dasar (RISKESDAS) 2013. Jakarta: 2013

[9] Kemenkes RI. Hasil Utama Riset Kesehatan Dasar (RISKESDAS) 2018. Jakarta: 2018.

[10] WHO. World Health Statistics 2014. Genevea: 2014.

[11] WHO. World Health Statistics 2015. Geneva: 2015.

[12] Heart Foundation. High Blood Pressure Statistics: Fact Sheet. Canberra: 2012.

[13] Warren N, Canaway R, Unantenne N, Manderson L. Taking control: Complementary and alternative medicine in diabetes and cardiovascular disease management. Heal SagePub [Internet] 2013;17(4):323-39. Available from: http://www.ncbi.nlm.nih.gov/pubmed/23014892

[14] Larkey L, Szalacha L, Rogers C, Jahnke R, Ainsworth B Measurement Pilot Study of the Meditative Movement Inventory (MMI). J Nurs Meas 2012;20(3):230-43.

[15] Taylor-Piliae RE, Haskell WL, Sivarajan Froelicher E Hemodynamic responses to a community-based Tai Chi exercise intervention in ethnic Chinese adults with cardiovascular disease risk factors. Eur J Cardiovasc Nurs 2006;5(2):165-74.

[16] Sato S, Makita S, Uchida R, Ishihara S, Masuda M. Effect of Tai Chi training on baroreflex sensitivity and heart rate variability in patients with coronary heart disease. Int Heart J 2010;51(4):238-41.

[17] Lu WA, Kuo CD. The Effect of Tai Chi Chuan on the Autonomic Nervous Modulation in Older Persons. Med Sci Sports Exerc 2013;35(12):1972-6.

[18] Lu X, Hui-Chan CWY, Tsang WWN. Effects of Tai Chi training on arterial compliance and muscle strength in female seniors: a randomized clinical trial. Eur J Prev Cardiol 2013;20(2):238-45.

[19] Yeh GY, Wang C, Wayne PM, Phillips R. The Effect of Tai Chi Exrcise on Blood Pressure: A Systematic Review. Prev Cardiol 2008;(11):82-9.

[20] Arthur HM, Patterson C, Stone JA. The role of complementary and alternative therapies in cardiac rehabilitation: a systematic evaluation. EurJ Cardiovasc PrevRehabil 2006;13(1741-8267 (Print)):3-9.

[21] Hsieh FY, Bloch DA, Larsen MD. A simple method of sample size calculation for linear and logistic regression. Stat Med [Internet] 1998;17(14):1623-34. Available from: http://www.ncbi.nlm.nih.gov/entrez/query.fcgi?cmd=Retriev $\mathrm{e} \& \mathrm{db}=\mathrm{P}$ ubMed\&dopt=Citation\&list_uids $=9699234 \% 5 \mathrm{Cn}$ (null)

[22] Chobanian A V. The Seventh Report of the Joint National Committee on Prevention, Detection, Evaluation, and Treatment of High Blood Pressure [Internet].
Bethesda: 2004. Available from:

https://www.nhlbi.nih.gov/files/docs/guidelines/jnc7full.pdf

[23] Yeh GY, McCarthy EP, Wayne PM, Stevenson LW, Wood MJ, Forman D, et al. Tai Chi Exercise in Patients With Chronic Heart Failure. Arch Intern Med 2011;171(8):750-7.

[24] Yeh GY, Roberts DH, Wayne PM, Davis RB, Quilty MT, Phillips RS. Tai Chi Exercise for Patients With Chronic Obstructive Pulmonary Disease: A Pilot Study. 2010;1475-82.

[25] Wayne PM. The Harvard Medical School Guide to Tai Chi: 12 Weeks to A Health Body, Strong Heart \& Sharp Mind. Boston: Harvard Health Publication; 2013.

[26] Balitbangkes Depkes RI. Pedoman Pengukuran dan Pemeriksaan. Jakarta: Depkes RI; 2007.

[27] Tortora GJ, Derrickson B. Principles of Anatomy and Physiology. 12th ed. Hoboken: John Wiley \& Sons, Inc.; 2009.

[28] Silverthorn D, Johnson B, Ober W, Garrison C, Silverthorn A. Human Physiology. 5th ed. San Fransisco: Pearson Education, Inc.; 2010.

[29] Wang C, Bannuru R, Ramel J, Kupelnick B, Scott T, Schmid CH. Tai Chi on psychological well-being: systematic review and meta-analysis. 2010; Eston R, Reilly T. Kinanthropometry and Exercise Physiology Laboratory Manual: Test, Procedures ad Data. 2nd ed. London: Routledge Taylor \& Francis Group; 2001. 